\section{ABCS}

How to cite this article: Silva et al. Evaluation of quality of life, functionality and disability in patients with systemic sclerosis in a university hospital. ABCS Health Sci. 2020;45:e020025. https://doi.org/10.7322/ abcshs.45.2020.1349

Received: Oct 22, 2019

Revised: Apr 17, 2020

Approved: May 28, 2020

Corresponding author: Andréa Tavares Dantas - Hospital das Clínicas - Universidade Federal de Pernambuco - Avenida Professor Moraes Rego, 1235 - Cidade Universitária, CEP: 50670-901 - Recife (PE), Brazil -

E-mail: andreatdantas@gmail.com

Declaration of interests: nothing to declare

This is an open access article distributed under the terms of the Creative Commons Attribution License

(C) 2020 Silva et al.

\title{
Evaluation of quality of life, functionality and disability in patients with systemic sclerosis in a University Hospital
}

Amanda Maria da Silva ${ }^{1}$, Letticia Cristina Santos Cardozo Roque ${ }^{2}$, Rafaela Silva Guimarães Gonçalves ${ }^{3}$, Angela Luzia Branco Pinto Duarte ${ }^{3}$, Angélica da Silva Tenório, Andréa Tavares Dantas ${ }^{3}$

${ }^{1}$ Curso de Fisioterapia, Universidade Federal de Pernambuco (UFPE) - Recife, Pernambuco, Brazil ${ }^{2}$ Programa de Mestrado, UFPE - Recife, Pernambuco, Brazil.

${ }^{3}$ Curso de Medicina, UFPE - Recife, Pernambuco, Brazil.

\section{ABSTRACT}

Introduction: Systemic sclerosis (SSc) is a chronic autoimmune disease characterized by progressive fibrosis of the skin and internal organs that promotes high morbidity and mortality. Objective: To evaluate the functionality, disability and quality of life of patients with systemic sclerosis and to compare the clinical forms of the disease. Methods: Cross-sectional, descriptive and analytical study performed at the Rheumatology Clinic of the Hospital das Clínicas of the Federal University of Pernambuco (HC-UFPE) from August 2018 to April 2019. The non-probabilistic, convenience sample consisted of 60 patients diagnosed with systemic sclerosis (SSc), followed at the Rheumatology outpatient clinic of the Hospital das Clínicas, Federal University of Pernambuco. To evaluate the outcomes, the following instruments were used: Cochin Hand Functional Scale (CHFS) for hand function; 12-Item ShortForm Health Survey (SF-12) for quality of life; and Scleroderma Health Assessment Questionnaire (SHAQ) for functionality and disability. Results: The mean results for CHFS, SHAQ, SF-12 Physical Component Summary and SF-12 Mental Component Summary were 14.5 (6.0-29.75), $1.01 \pm 0.56,35.04 \pm 8.09,40.94 \pm 10.56$, respectively. There were no significant differences in CHFS outcomes between patients with diffuse and limited forms of SSc, SHAQ and the mental component of SF-12. However, in the physical component of SF-12, a better score was found in patients with the diffuse form of the disease $(p=0.04)$. Conclusion: Patients with SSc present an important impairment of hand function, quality of life and functional capacity, and those with limited cutaneous form present worse scores of the physical component in the evaluation of quality of life.

Keywords: sclerosis systemic; scleroderma, diffuse; quality of life; motor skills; hand strength.

\section{INTRODUCTION}

Systemic sclerosis (SSc) is an autoimmune disease of unknown etiology, which is characterized by excess collagen synthesis, leading to fibrosis of the skin and organs ${ }^{1}$. It is a rare disease, with a prevalence of approximately 10 cases per 100,000 inhabitants, 
and its incidence is higher in females ${ }^{2,3}$. There are two clinical forms of SSc classification, according to the extent of cutaneous involvement: limited cutaneous and diffuse cutaneous. In the limited cutaneous there is a thickening of the skin at the extremities (face, forearm and hands, legs and feet) and in the diffuse cutaneous the most proximal regions of the limbs, trunk and abdomen are affected ${ }^{2}$. The involvement of organs is relatively minor in the limited cutaneous form ${ }^{4}$.

Regarding muscle changes, the presence of myopathy is described in between $20 \%$ and $86 \%$ of patients, arthralgia in $23 \%$ to $81 \%$ and synovitis in $15 \%$ to $20 \%{ }^{5}$. The range of motion may be decreased, causing a wave of contractures whose prevalence evaluated by physical examination varies from $24 \%$ to $56 \% 5$. Therefore, individuals with SSc can show loss of mobility and decrease of muscle strength, as well as contractures and deformities of the hands. All of these changes may cause significant impairment in functionality and quality of life, and cause an increase in overall disability, impairing daily activities ${ }^{6,7}$.

There is no curative treatment for this disease. It is important to reduce symptoms, disability and improve the quality of life of SSc patients. In this sense, interdisciplinary treatment with physicians, psychologists, physiotherapists, occupational therapists and social workers is important ${ }^{7}$. Physiotherapy plays an important role in the prevention of muscle and joint disorders, such as contractures and decreased range of motion, as well as contributing to the maintenance of functionality in the affected systems ${ }^{8}$.

Thus, there is a need to carry out studies aiming at identifying functional and quality of life compromises in patients with SSc, through the application of validated assessment instruments for this population. Obtaining greater knowledge about the degree of impairment of these factors due to the disease may contribute to the planning of more resolutive treatment approaches for these patients.

The present study aims to evaluate the functionality, disability and quality of life of patients with systemic sclerosis, to compare the differences between clinical forms and to verify the association with clinical manifestations of the disease.

\section{METHODS}

The present study is characterized as a cross-sectional, descriptive and analytical study. The patients were recruited at the rheumatology outpatient clinic of the Hospital das Clínicas of the Federal University of Pernambuco, Brazil (HC-UFPE) from August 2018 to April 2019.

The sample was non-probabilistic, of convenience. The patients with SSc included in the study had the classification criteria of ACR/EULAR $2013^{9}$ and were 18 years or older. The exclusion criteria were: diagnosis of localized scleroderma; known diagnosis of mental retardation, dementia or neoplasia.
Clinical data of patients were obtained from medical records. Lung fibrosis was defined using high-resolution computed tomography (HRCT); esophagus involvement was determined by scintilography or endoscopy; proximal muscle weakness and elevated serum creatine kinase indicated muscle involvement were recorded. Pulmonary artery pressure was estimated by Doppler echocardiogram; pressures above $35 \mathrm{mmHg}$ were interpreted as pulmonary hypertension.

In order to evaluate the functionality, the Cochin Hand Functional Scale (CHFS) was used, a questionnaire developed in France and validated in Portuguese that aims to evaluate the functionality of the hands and has been applied in patients $\mathrm{s}^{8,10}$ with SSc. It consists in 18 questions that cover manual functional activities, whose answers range from 0 (patient who performs the activity without difficulty) to 5 (patient who is unable to do the activity). The final score is obtained by adding the results of all items ${ }^{11,12}$.

Quality of life was evaluated through the 12-item ShortForm Health Survey (SF-12), a more concise version of the Medical Outcomes Study 36-Item Short-Form Health Survey (SF-36). It is an instrument with 12 items that assesses functional capacity, physical aspects, pain, general health, vitality, social aspects, emotional aspects and mental health; these items present a possible set of responses that is distributed on a Likert scale. The final calculation is done from a questionnaire algorithm, with two domains being calculated: physical (Physical Component Summary, or PCS) and mental (Mental Component Summary, or MCS). Scores ranged from 0 to 100 (the higher the result, the better the SF-12) ${ }^{13}$. It was applied to evaluate SF-12 in several diseases ${ }^{14,15}$ and was previously applied to $\mathrm{SSc}^{16}$.

The disability was evaluated by the Scleroderma Health Assessment Questionnaire (SHAQ), a self-administered questionnaire consisting of 20 questions evaluating functional capacity, as well as specific symptoms of the disease: Raynaud's phenomenon, digital ulcers, gastrointestinal and pulmonary symptoms, and the overall assessment of SSc severity. To obtain the result, the value is multiplied by 0.2 , and the final score from 0 to 3 indicates minimal to severe disability ${ }^{17}$.

The eligibility criteria were verified and the informed consent form was applied. Demographic and clinical information was obtained from the interview of the patients by two duly trained evaluators and data collection recorded in the medical records, and then the SF-12, CHFS and SHAQ questionnaires were applied.

\section{Statistical analysis}

GraphPad Prism 6.0 software (GraphPad Software Inc., San Diego, California, US) was used for data analysis. The D'Agostino test was used to evaluate the normality of the sample. The expression of the 
continuous variables results was done by the means and standard deviation (SD) for the samples with normal distribution and median with interquartile variation for those with non-normal distribution. To verify possible differences between means, students t-tests were used for independent samples, when the distribution was Gaussian; in the cases of samples with non-normal distribution the non-parametric Mann-Whitney t-test was used. Categorical variables were assessed using the chi-square test or Fisher's exact test. Association between two continuous variables was evaluated by the Spearman test, being considered a weak correlation if $0<r \leq 0.35$, moderate $0.35<r \leq 0.67$ and strong if $0.67<\mathrm{r} \leq 1$. Values of $\mathrm{p}<0.05$ were considered significant.

The study was approved by the Committee on Ethics in Research of Human Beings (CAAE-00999218.0.3001.5208), in accordance with the precepts of the Brazilian Health Council. Informed consent was obtained from all individual participants included in the study.

\section{RESULTS}

This study had a total of 60 patients, most of whom were female (91.7\%), with a mean age of 47.1 years and a mean diagnosis time of 107.2 months. The limited cutaneous form was the most observed in the participant population, and the Raynaud phenomenon and esophageal dysfunction were the most common clinical manifestations, as shown in Table 1.

The results regarding the evaluation of the functionality, disability and quality of life are described in Table 2. In the comparison between the clinical forms, it was observed that the results of CHFS showed no difference between the diffuse and limited forms of SSc, as well as the SHAQ and the mental component of SF-12. The physical component presented a better result in the diffuse form of the disease $(\mathrm{p}=0.04)$.

There was no association between the CHFS, SHAQ and SF-12 scores and the variables of age, time of diagnosis and the presence of specific clinical manifestations of the disease (Table 3). Similarly, associations between the respective scores were not observed (Table 4).

\section{DISCUSSION}

The present study demonstrated that patients with SSc have low hand function, quality of life and functional capacity. The

Table 1: Demographic and clinical characteristics of patients with systemic sclerosis $(n=60)$

\begin{tabular}{|c|c|c|c|}
\hline Variables & $\begin{array}{c}\text { Total } \\
(N=60)\end{array}$ & $\begin{array}{l}\text { Diffuse } \\
(n=23)^{*}\end{array}$ & $\begin{array}{l}\text { Limited } \\
(n=32)^{\star}\end{array}$ \\
\hline Age (Years) (mean $\pm S D)$ & $47.1 \pm 12.9$ & $44.8 \pm 14.1$ & $48.3 \pm 11.7$ \\
\hline Women n (\%) & $55(91.7)$ & $20(86.9)$ & $30(93.7)$ \\
\hline Diagnostic time (months) mean $( \pm S D)$ & $107.2 \pm 81.6$ & $104.5 \pm 86.5$ & $117.0 \pm 80.1$ \\
\hline \multicolumn{4}{|l|}{ Clinical form n (\%) } \\
\hline Diffuse cutaneous & $23(38.3)$ & - & - \\
\hline Cutaneous limited & 32 (53.3) & - & - \\
\hline No information & $5(8.4)$ & - & - \\
\hline \multicolumn{4}{|l|}{ Clinical manifestations $\mathrm{n}(\%)$} \\
\hline Raynaud's Phenomenon & $52(86.7)$ & $20(86.9)$ & $28(87.5)$ \\
\hline Digital Ulcers & 20 (33.3) & $7(30.4)$ & $12(37.5)$ \\
\hline Arthritis & $17(28.3)$ & $6(26.1)$ & $8(25.0)$ \\
\hline Myositis & $11(18.3)$ & $6(26.1)$ & $5(15.6)$ \\
\hline Esophageal dysmotility & $48(80.0)$ & $20(86.9)$ & $25(78.1)$ \\
\hline Lung fibrosis & $41(68.3)$ & $18(78.2)$ & $20(62.5)$ \\
\hline Pulmonary hypertension & $4(6.7)$ & $1(4.3)$ & $3(9.4)$ \\
\hline
\end{tabular}

Table 2: Functional outcome (CHFS), disability (SHAQ) and quality of life (SF-12) results in patients with systemic sclerosis and comparison between limited cutaneous and diffuse cutaneous clinical forms.

\begin{tabular}{|c|c|c|c|c|}
\hline & $\begin{array}{c}\text { Total } \\
(n=60)\end{array}$ & $\begin{array}{l}\text { Diffuse } \\
(n=23)^{\star}\end{array}$ & $\begin{array}{l}\text { Limited } \\
(n=32)^{\star}\end{array}$ & $\mathbf{P}$ \\
\hline CHFS (median, IQR) & $14.5(6.0-29.75)$ & $15.0(6.0-30.0)$ & $16.0(6.25-33.25)$ & 0.76 \\
\hline SHAQ (mean $\pm S D)$ & $1.01 \pm 0.56$ & $0.89 \pm 0.55$ & $1.13 \pm 0.57$ & 0.13 \\
\hline SF-12 PCS (mean $\pm S D$ ) & $35.04 \pm 8.09$ & $37.84 \pm 8.59$ & $33.33 \pm 7.52$ & 0.04 \\
\hline SF-12 MCS (mean $\pm S D)$ & $40.94 \pm 10.56$ & $42.8 \pm 10.83$ & $39.27 \pm 9.83$ & 0.21 \\
\hline
\end{tabular}

CHFS: Cochin Hand Functional Scale, SHAQ: Scleroderma Health Assessment Questionnaire, SD: standard deviation, PCS: Physical Component Summary, MCS: Mental Component Summary, SF-12: 12-Item Short-Form Health Survey, IQR: Interquartile Range.

*Patients not classified were excluded from this analysis. 
Table 3: Evaluation of functional scores (CHFS), disability (SHAQ) and quality of life (SF-12) according to demographic variables and clinical manifestations of the disease $(n=60)$.

\begin{tabular}{|c|c|c|c|c|}
\hline & CHFS & SHAQ & SF-12 PCS & SF-12 MCS \\
\hline \multirow{3}{*}{ Age } & $R=-0.17$ & $R=-0.26$ & $\mathrm{R}=0.06$ & $R=0.23$ \\
\hline & $\mathrm{Cl}-0.41$ to 0.09 & $\mathrm{Cl}-0.48$ to -0.01 & $\mathrm{Cl}:-0.19$ to 0.31 & $\mathrm{Cl}-0.03$ to 0.46 \\
\hline & $P=0.19$ & $\mathrm{P}=0.05$ & $P=0.64$ & P 0.08 \\
\hline \multirow{3}{*}{ Diagnose time } & $R=-0.03$ & $R=-0.11$ & $R=-0.01$ & $\mathrm{R}=0.16$ \\
\hline & $\mathrm{Cl}-0.29$ to 0.22 & $\mathrm{Cl}-0.36$ to 0.15 & $\mathrm{Cl}-0.27$ to 0.24 & $\mathrm{Cl}-0.10$ to 0.40 \\
\hline & $P=0.80$ & $P=0.41$ & $P=0.93$ & $P=0.23$ \\
\hline Women & $15.0(6.0-31.0)$ & $1.03 \pm 0.56$ & $34.97 \pm 8.20$ & $40.96 \pm 10.81$ \\
\hline \multirow[t]{2}{*}{ Men } & $14.0(6.5-27.0)$ & $0.79 \pm 0.50$ & $35.81 \pm 7.53$ & $40.72 \pm 8.28$ \\
\hline & $P=0.95$ & $P=0.37$ & $P=0.83$ & $P=0.96$ \\
\hline Raynaud + & $15.0(6.0-30.5)$ & $1.01 \pm 0.57$ & $35.23 \pm 8.18$ & $40.75 \pm 11.18$ \\
\hline \multirow[t]{2}{*}{ Raynaud - } & $14.0(7.0-30.0)$ & $1.08 \pm 0.47$ & $32.97 \pm 8.06$ & $41.98 \pm 5.67$ \\
\hline & $P=0.90$ & $P=0.76$ & $P=0.50$ & $P=0.78$ \\
\hline Ulcers + & $17.0(8.75-33.0)$ & $1.06 \pm 0.56$ & $33.85 \pm 8.13$ & $41.89 \pm 8.01$ \\
\hline \multirow[t]{2}{*}{ Ulcers - } & $13.0(4.75-29.5)$ & $0.99 \pm 0.56$ & $35.22 \pm 8.07$ & $40.90 \pm 11.54$ \\
\hline & $P=0.20$ & $P=0.66$ & $P=0.54$ & $P=0.73$ \\
\hline Esophagus + & $17.0(7.0-30.75)$ & $1.07 \pm 0.54$ & $35.34 \pm 8.33$ & $41.70 \pm 10.88$ \\
\hline \multirow[t]{2}{*}{ Esophagus - } & $7.0(0-13.0)$ & $0.79 \pm 0.55$ & $33.29 \pm 7.33$ & $37.37 \pm 9.20$ \\
\hline & $P=0.06$ & $P=0.13$ & $P=0.46$ & $P=0.23$ \\
\hline Lung + & $16.0(6.0-29.0)$ & $1.03 \pm 0.54$ & $35.31 \pm 8.27$ & $41.68 \pm 10.71$ \\
\hline \multirow[t]{2}{*}{ Lung - } & $13.0(5.75-35.0)$ & $0.99 \pm 0.58$ & $34.15 \pm 7.99$ & $39.09 \pm 10.56$ \\
\hline & $P=0.89$ & $P=0.79$ & $P=0.62$ & $P=0.39$ \\
\hline Pulm. hypert. + & $23.5(15.75-50.0)$ & $1.26 \pm 0.82$ & $30.89 \pm 11.39$ & $37.81 \pm 9.19$ \\
\hline \multirow[t]{2}{*}{ Pulm. hypert. - } & $13.0(6.0-30.0)$ & $1.00 \pm 0.53$ & $35.25 \pm 7.91$ & $41.12 \pm 10.78$ \\
\hline & $P=0.17$ & $P=0.38$ & $P=0.30$ & $P=0.55$ \\
\hline Arthritis + & $17.0(7.0-34.0)$ & $1.16 \pm 0.46$ & $34.20 \pm 8.62$ & $38.52 \pm 10.30$ \\
\hline \multirow[t]{2}{*}{ Arthritis - } & $12.5(3.25-29.0)$ & $0.96 \pm 0.58$ & $35.26 \pm 8.01$ & $41.85 \pm 10.75$ \\
\hline & $P=0.18$ & $P=0.22$ & $P=0.65$ & $P=0.28$ \\
\hline Myositis + & $14.0(6.0-40.0)$ & $1.11 \pm 0.55$ & $34.28 \pm 7.15$ & $39.80 \pm 10.65$ \\
\hline \multirow[t]{2}{*}{ Myositis - } & $15.0(5.25-29.0)$ & $1.00 \pm 0.56$ & $35.11 \pm 8.40$ & $41.14 \pm 10.74$ \\
\hline & $P=0.45$ & $P=0.57$ & $P=0.76$ & $P=0.71$ \\
\hline
\end{tabular}

Pulm. hypert: Pulmonary Hypertension, CHFS: Cochin Hand Functional Scale, SD: standard deviation, PCS: physical component summary, MCS: mental component summary, SF-12: 12-Item Short-Form Health Survey, SHAQ: Scleroderma Health Assessment Questionnaire, IQR: interquartile range; Cl: confidence interval.

Table 4: Correlation between CHFS, SHAQ and quality of life scales.

\begin{tabular}{|l|c|c|c|}
\hline SCALES & $r$ & Cl & $p$ \\
\hline CHFS X SHAQ & 0.66 & 0.49 to 0.79 & $<0.0001$ \\
\hline CHFS X SF-12 PCS & 0.31 & -0.53 to -0.05 & 0.02 \\
\hline CHFS X SF-12 MCS & 0.28 & -0.51 to -0.02 & 0.03 \\
\hline
\end{tabular}

CHFS: Cochin Hand Functional Scale, SF-12: 12-Item Short-Form Health Survey, PCS: physical component summary, MCS: mental component summary, SHAQ: Scleroderma Health Assessment Questionnaire, $\mathrm{Cl}$ : confidence interval.

involvement of the hands due to cutaneous, vascular and articular alterations represents one of the main causes of impairment of the functionality and, consequently, of incapacity attributed to the disease and is associated with an important decrease in quality of life $\mathrm{e}^{18}$

Regarding the functionality of the hand, the results of the present study described in the literature in other populations. A multicenter study that evaluated 1193 SSc patients found a mean CHFS score of $13.3 \pm 16.1$ points $^{18}$. Similarly, another European multicenter observational study showed a median 18.7 \pm 20.7 CHFS score, considering only those patients who reported some hand involvement $(\mathrm{CHFS}>0)^{19}$. Our study obtained an average of 14.5 in CHFS, indicating a loss in functionality; it is important to emphasize that these patients have difficulties in specific tasks, like buttoning a shirt and peeling fruit, that prevents daily domestic tasks. It is also emphasized that the impairment of hand function in SSc can be similar or even worse than that described in other diseases that present with joint involvement of the hands, such as rheumatoid arthritis ${ }^{20}$ or osteoarthritis.

Kwakkenbos et al. ${ }^{18}$ described an association between higher CHFS scores and females, diffuse cutaneous form, and severity of Raynaud's phenomenon. Peytrignet et al. ${ }^{19}$ found an association between reduced hand function and the presence of digital ulcers, pulmonary fibrosis and severity of the Raynaud phenomenon. In the present study, no difference was found between the limited and diffuse cutaneous forms. Although the score was worse in patients with Raynaud's phenomenon, digital ulcers, esophageal involvement, pulmonary fibrosis, pulmonary hypertension and arthritis, these differences were not statistically significant. 
Considering the severity of SSc and its multiple forms of presentation, patients' quality of life tends to be severely compromised. A Brazilian study of 46 patients with SSc showed scores on the physical and mental components of the SF-12 of $37.3 \pm 9.0$ and $41.1 \pm 10.8$, respectively ${ }^{16}$, like that found in the present study. When compared to the scores obtained in other diseases, it is observed that they are similar to those found in diseases considered serious and of reserved prognosis, such as advanced lung cancer ${ }^{21}$.

Although some studies describe a greater impairment of quality of life in diffuse cutaneous form ${ }^{22,23}$, we found a worse score for the physical component of SF-12 in limited cutaneous form. This apparently contradictory result may be related to clinical differences between the two forms whose evaluation was not objective of the present study. The presence of clinical manifestations, such as pulmonary hypertension, Raynaud's phenomenon and gastrointestinal impairment have already been described as predictors of poorer quality of life in SSc patients ${ }^{23}$, but these associations were not identified in our population. Although the clinical compromises caused by the disease may have different impacts on different populations, it is possible that our sample was not enough to detect these associations.

Regarding the assessment of disability, our results show global scores like those described in other populations. Jaeger et al. ${ }^{24}$ evaluated 944 patients and found a mean SHAQ score of $0.87 \pm 0.66$. This same study described an association between greater disability and the presence of myopathy, digital ulcers and gastrointestinal symptoms, a finding that was not observed in the present study.

The present study represents the first evaluation in Brazil of parameters of hand functionality, quality of life and disability of SSc patients and their respective associations with clinical manifestations of the disease. However, it has some limitations. The use of a sample of non-probabilistic convenience may not have allowed significant representativeness of the population of SSc patients. The cross-sectional design of the study can identify associations but does not allow inferring causality between them.

Patients with SSc present an important impairment of hand functionality, quality of life and functional capacity. Patients with limited cutaneous form presented worse scores of the physical component in the evaluation of quality of life. No associations were identified between these parameters and demographic or clinical characteristics of the patients. Additional studies with greater inclusion of patients, preferably multicentric, are necessary for a better characterization of these aspects in Brazilian patients.

\section{REFERENCES}

1. Cutolo M, Soldano S, Smith V. Pathophysiology of systemic sclerosis: current understanding and new insights. Expert Rev Clin Immunol. 2019;15(7):753-64.

http://doi.org/10.1080/1744666X.2019.1614915

2. Sticherling M. Systemic sclerosis-dermatological aspects. Part 1: Pathogenesis, epidemiology, clinical findings. J Dtsch Dermatol Ges. 2012;10(10):705-18.

https://doi.org/10.1111/j.1610-0387.2012.07999.x

3. Justo AC, Guimarães FS, Ferreira AS, Soares MS, Bunn PS, Lopes AJ. Muscle function in women with systemic sclerosis: Association with fatigue and general physical function. Clin Biomech. 2017;47:33-9.

https://doi.org/10.1016/j.clinbiomech.2017.05.011

4. Kucharz EJ, Magdalena KM. Systemic sclerosis sine scleroderma. Adv Clin Exp Med. 2017:26(5):875-880. http://doi.org/10.17219/acem/64334

5. Lórand V, Czirják L, Minier T. Musculoskeletal involvement in systemic sclerosis. Presse Med. 2014;43(10):e315-28 http://doi.org/10.1016/j.lpm.2014.03.027

6. Bretterklieber A, Painsi C, Avian A, Wutte N, Aberer E. Impaired quality of life in patients with systemic sclerosis compared to the general population and patients with other chronic dermatoses. BMC Res Notes. 2014;7:594 http://doi.org/10.1186/1756-0500-7-594

7. Almeida C, Almeida I, Vasconcelos C. Quality of life in systemic sclerosis. Autoimmun Rev. 2015:14(12):1087-96. http://doi.org/10.1016/j.autrev.2015.07.012
8. Horváth J, Bálint Z, Szép E, Deiszinger A, Minier T, Farkas N, et al. Efficacy of intensive hand physical therapy in patients with systemic sclerosis. Clin Exp Rheumatol. 2017;106(4):159-66.

9. van den Hoogen F, Khanna D, Fransen J, Johnson RS, Baron M, Tyndall A, et al. 2013 classification criteria for systemic sclerosis: An american college of rheumatology/European league against rheumatism collaborative initiative. Ann Rheum Dis. 2013;72(11):1747-55

http://doi.org/10.1136/annrheumdis-2013-204424

10. Landim SF, Bertolo MB, Abreu MFM, Del Rio AP, Mazon CC, MarquesNeto JF, et al. The evaluation of a home-based program for hands in patients with systemic sclerosis. J Hand Ther. 2019;32(3):313-21. http://doi.org/10.1016/j.jht.2017.10.013

11. Chiari A, Sardim SCC, Natour J. Translation, cultural adaptation and reproducibility of the Cochin Hand Functional Scale questionnaire for Brazil. Clinics. 2011;66(5):731-6. http://dx.doi.org/10.1590/S1807-59322011000500004

12. Nguyen CB, Bérezné A, Mestre-Stanislas C, Lefevre-Colau MM Rannou F, Guillevin L, et al. Changes over time and responsiveness of the cochin hand function scale and mouth handicap in systemic sclerosis scale in patients with systemic sclerosis. Am J Phys Med Rehabil. 2016;95(12):e189-97. http://dx.doi.org/10.1097/PHM.0000000000000611

13. Shou J, Ren L, Wang H, Yan F, Cao X, Wang H, et al. Reliability and validity of 12-item Short-Form health survey (SF-12) for the health status of Chinese community elderly population in Xujiahui district of Shanghai. Aging Clin Exp Res. 2015;28(2):339-46. http://dx.doi.org/10.1007/s40520-015-0401-9 
14. Corbacho MI, Dapueto JJ. Assessing the functional status and quality of life of patients with rheumatoid arthritis. Rev Bras Reumatol. 2010;50(1):31-43.

http://dx.doi.org/10.1590/S0482-50042010000100004

15. Westergren A, Hagell P. Measurement properties of the 12-item shortform health survey in stroke. J Neurosci Nurs. 2014;46(1):34-45. http://doi.org/10.1097/JNN.0000000000000027

16. Andrade TL, Camelier AA, Rosa FW, Santos MP, Jezler S, Silva JLP. Applicability of the 12-Item Short-Form Health Survey in patients with progressive systemic sclerosis. J Bras Pneumol. 2007;33(4):414-22.

http://dx.doi.org/10.1590/S1806-37132007000400010

17. Rocha LF, Marangoni RG, Sampaio-Barros PD, Levy-Neto $\mathrm{M}$, Yoshinari $\mathrm{NH}$, Bonfa $\mathrm{E}$, et al. Cross-cultural adaptation and validation of the Brazilian version of the Scleroderma Health Assessment Questionnaire (SHAQ). J Clin Rheumatol. 2014;33(5):699-706

http://doi.org/10.1007/s10067-013-2370-8

18. Kwakkenbos L, Sanchez TA, Turner KA, Mouthon L, Carrier ME, Hudson $\mathrm{M}$, et al. The association of sociodemographic and disease variables with hand function: a Scleroderma Patientcentered Intervention Network cohort study. Clin Exp Rheumatol. 2018;113(4):88-94.

19. Peytrignet S, Denton CP, Lunt M, Hesselstrand R, Mouthon L, Silman A, et al. Disability, fatigue, pain and their associates in early diffuse cutaneous systemic sclerosis: the European Scleroderma Observational Study. Rheumatology. 2018;57(2):370-81. http://doi.org/10.1093/rheumatology/kex410

20. Silva GS, Almeida Lourenço M, Assis MR. Hand strength in patients with RA correlates strongly with function but not with activity of disease. Adv Rheumatol. 2018;58:20. http://dx.doi.org/10.1186/s42358-018-0020-1

21. Barney BJ, Wang XS, Lu C, Liao Z, Johnson VE, Cleeland CS, et al. Prognostic value of patient-reported symptom interference in patients with late-stage lung cancer. Qual Life Res. 2013;22(8):2143-50.

http://doi.org/10.1007/s11136-013-0356-2

22. Hudson $M$, Thombs $B D$, Steele $R$, Panopalis $P$, Newton $E$, Baron $\mathrm{M}$, et al. Health-related quality of life in systemic sclerosis: a systematic review. Arthritis Care Res. 2009;61(8):1112-20. http://doi.org/10.1002/art.24676

23. Morrisroe K, Hudson M, Baron M, Vries-Bouwstra J, Carreira PE, Wuttge DM, et al. Determinants of health-related quality of life in a multinational systemic sclerosis inception cohort. Clin Exp Rheumatol. 2018;36(113):53-60.

24. Jaeger VK, Distler O, Maurer B, Czirják L, Lóránd V, Valentini G, et al. Functional disability and its predictors in systemic sclerosis: a study from the DeSScipher project within the EUSTAR group. Rheumatology. 2018;57(3):441-50. http://doi.org/10.1093/rheumatology/kex182 